\title{
ASSESSMENT OF HEAT UNIT AVAILABILITY AND POTENTIAL LINT YIELD OF COTTON IN OKLAHOMA
}

\author{
B. Masasi, S. Taghvaeian, P. H. Gowda, D. N. Moriasi, P. J. Starks
}

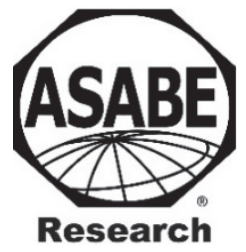

\section{HighLIGHTS}

- Water availability challenges have increased interest in cotton production in Oklahoma.

- An attempt was made to understand the feasibility of growing cotton in all counties of Oklahoma.

- Many areas in Oklahoma have sufficient thermal conditions for cotton production.

- Potential cotton lint yields generally increase from northern to southern areas of the state.

ABSTRACT. With the expansion of planted area, Oklahoma is increasingly becoming a major cotton producing state in the United States (U.S.). However, the feasibility of growing cotton in all counties of Oklahoma has not been determined. In this study, a heat unit based model was used to estimate the potential cotton lint yields (PCLYs) for all 77 counties of Oklahoma using 38 years (1981-2018) of air temperature data. PCLYs were estimated for optimal (no stress) conditions. The long-term total heat units (THUs) were more than $1000^{\circ} \mathrm{C} \cdot \mathrm{d}$ in $99 \%$ of counties, an indication that many areas in Oklahoma may have conducive thermal conditions for cotton production in most years. Similar to the THUs, the PCLYs generally increased from the northern to the southern counties of the state, and long-term averages ranged from 407 to $2472 \mathrm{~kg} \mathrm{ha} \mathrm{g}^{-1}$. About $97 \%$ of the counties achieved long-term average PCLYs of at least $1000 \mathrm{~kg} \mathrm{ha}{ }^{-1}$. However, the results showed significant interannual variability of the estimated PCLYs in each county over the 38-year period. Low and high PCLYs mostly coincided with years characterized by cool and warm growing seasons, respectively. Reductions of PCLY ranging from $6 \%$ to $29 \%$ were observed when planting was delayed by just one week from the optimized planting date. This indicates that cotton producers need to carefully consider planting date to maximize cotton lint yield. As THUs were the only factor considered for calculating PCLYs in this study, future research should incorporate other variables such as rainfall and heat stress to improve PCLY estimations.

Keywords. Air temperature, Planting date, Soil temperature, Yield gap, Yield variability.

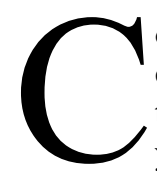

otton (Gossypium hirsutum L.) is one of the major crops in Oklahoma and contributes significantly to the state's economy (Franke et al., 2009). Over the years, Oklahoma has risen in the ranks to become one of the leading cotton producing states in the United

The authors have paid for open access for this article. This work is licensed under a Creative Commons Attribution-NonCommercial-NoDerivatives 4.0 International License https://creative commons.org/licenses/by-nc-nd/4.0/.

Submitted for review in March 2020 as manuscript number NRES 14006; approved for publication as a Research Article by the Natural Resources \& Environmental Systems Community of ASABE in September 2020.

Mention of company or trade names is for description only and does not imply endorsement by the USDA. The USDA is an equal opportunity provider and employer.

The authors are Blessing Masasi, Postdoctoral Fellow, Department of Biosystems and Agricultural Engineering, Oklahoma State University, Stillwater, Oklahoma; Saleh Taghvaeian, Associate Professor, Department of Biosystems and Agricultural Engineering, Oklahoma State University, Stillwater, Oklahoma; Prasanna H. Gowda, Associate Area Director, USDA-ARS Southeast Area, Stoneville, Mississippi; Daniel N. Moriasi, Research Hydrologist, USDA-ARS Grazinglands Research Laboratory, El Reno, Oklahoma; and Patrick J. Starks, Research Soil Scientist, USDAARS Grazinglands Research Laboratory, El Reno, Oklahoma. Corresponding author: Blessing Masasi, 111 Ag Hall, Stillwater, OK 74078; phone: 405-762-0316; email: blessing.masasi@okstate.edu.
States (USDA-NASS, 2019). According to Boyd (2019), the planted cotton area in Oklahoma increased significantly from 123,430 ha in 2016 to 236,740 ha in 2017 , making it the third largest cotton producing state in the U.S. behind Texas and Georgia. Cotton production in Oklahoma is predominantly in the southwest region of the state (Evers et al., 1998; Franke et al., 2009). However, there has been an increasing interest by producers in northern and Panhandle sections of the state where cotton growing seasons are more likely to be shortened by suboptimal thermal conditions (Esparza et al., 2007; Boyd, 2019). According to Gowda et al. (2007), the interest in cotton production in regions such as the Oklahoma Panhandle could be largely attributed to improvements in cotton genetics, particularly the development of early maturing varieties. Additionally, cotton is considered a relatively drought and salinity tolerant crop compared to other major crops like corn and soybean (Esparza et al., 2007; Boyd, 2019). As such, water scarcity, resulting from excessive abstractions of groundwater resources, recurrent droughts, and/or poor quality surface water resources could be another driving factor for the increased interest in cotton production in some parts of Oklahoma (Masasi et al., 2019).

Despite the increased interest in cotton cultivation in Oklahoma, there is little information available on its production 
feasibility across all 77 counties of the state. One approach that can be used to establish the physical and financial feasibility of growing cotton is to estimate potential cotton lint yield for all counties and regions of Oklahoma. Evans and Fischer (1999) defined potential yield as the maximum yield that could be attained by a crop in a given environment. According to Constable and Bange (2015), potential crop yield data are important in identifying crop production constraints, which could assist producers with determining production viability and making critical management decisions. In addition, the difference between potential and actual yields indicates yield gap, which is valuable for intensifying production, informing policy, and prioritizing research (Van Ittersum et al., 2013; Van Wart et al., 2013a). Moreover, potential yield data could be used as a baseline to study the effects of climate change (Van Wart et al., 2013b).

Many studies have reported that air temperature is one of the most critical factors that define crop yield potential (Van Wart et al., 2013a; Ullah et al., 2017). For cotton, air temperature during the growing season has a dominant influence on growing season length. Wanjura and Barker (1985) determined air temperature as the main environmental factor that controls the rate of lint accumulation. Other researchers have reported that air temperature affects cotton growth rates, fruiting, lint yield, and fiber quality, which is why cotton normally has a higher yield potential in areas characterized by long and hot seasons (Constable and Shaw, 1988; Tolk and Howell, 2010; Munir, 2014). Air temperature for crop growth is generally expressed in heat units, defined as the temperature accumulation occurring within daily lower and upper thresholds (Glade et al., 1996). Several previous studies have shown a strong influence of accumulated heat units on the overall attained cotton yields (Peng et al., 1989; Morrow and Krieg, 1990; Ullah et al., 2017). Cotton lint yield was found to have a strong positive linear relationship with accumulated heat units when water availability was not limiting (Wanjura et al., 2002; Gwathmey et al., 2011; Parthasarathi et al., 2013; Masasi et al., 2020).

Potential crop yield is generally estimated for optimal conditions (Evans and Fischer; 1999; Constable and Bange, 2015). Under non-water stress conditions, about $1450^{\circ} \mathrm{C} \cdot \mathrm{d}$ heat units from planting to maturity are required to maximize cotton lint yield at $15.6^{\circ} \mathrm{C}$ base temperature (Gowda et al., 2007, Mauget et al., 2019). However, in the Southern High Plains region, Howell et al. (2004) reported that cotton can be grown economically with approximately $1000^{\circ} \mathrm{C} \cdot \mathrm{d}$ heat units. Based on the physiology of recent cotton cultivars, Gowda et al. (2007) explained that one mature boll and additional four bolls at $85 \%$ maturity may be produced by a cotton plant at $1000^{\circ} \mathrm{C} \cdot \mathrm{d}$ heat units and that crop termination at this stage would reduce the cotton lint yield by only $1 \%$. By assuming the base temperature for cotton to be a conservative parameter (Supak, 1984), that is to say no varietal response to base temperature, Gowda et al. (2007) developed relationships between accumulated heat units and the potential cotton lint yield. Since these relationships are based on the physiological characteristics of cotton, they can be useful in other areas.
Apart from the growing season thermal conditions, the planting date is another critical factor that has to be considered for estimating the lint yield potential of cotton (Mauget et al., 2019). Van Ittersum et al. (2013) emphasized the importance of using optimum or recommended planting dates in estimating potential crop yield. The planting date for cotton significantly influences seedling establishment and hence is a critical determinant of lint yield potential (Boquet and Clawson, 2009). Previous studies have highlighted that planting cotton too early poses the risks of poor seedling emergence due to low soil temperatures, but could increase the length of the growing season in terms of cumulative heat units (Larson and Mapp, 1997; Marek and Bordovsky, 2006). However, planting late allows seeds to be placed in relatively warmer soils and enhances germination, but would reduce the growing season in terms of total heat units (THU) (Boman and Lemon, 2005; Boquet and Clawson, 2009).

As highlighted earlier, the area under cotton production in Oklahoma is growing due to this crop's potential to optimize irrigation under the current water scarcity challenges. However, there is limited information on the thermal feasibility and the potential cotton lint yield that can be achieved under ideal management conditions in Oklahoma and other major cotton producing states in the U.S. (Esparza et al., 2007; Gowda et al., 2007). Having such information would allow cotton producers to compare the viability of cotton production with other alternative crops. Additionally, this information will assist producers to make decisions about allocating their limited resources in the most efficient way possible. Moreover, the knowledge of potential cotton lint yield is vital for producers to set up realistic yield goals, plan appropriate management practices, and decide the extent of risk they can take without experiencing financial losses (Constable and Bange, 2015). The goal of this study was to estimate the potential cotton lint yield for all counties and climate divisions of Oklahoma over a long-term period. The more specific objectives were: (i) to estimate the dynamic planting dates of cotton for all counties of Oklahoma using soil temperature and forecasts of air temperature and heat units; (ii) to estimate the long-term heat unit availability and potential cotton lint yield for all counties and climate divisions of Oklahoma; and, (iii) to determine the effects of planting date on potential cotton lint yield.

\section{Materials AND Methods}

\section{STUDY AREA}

The study considered all 77 counties of Oklahoma. The countywide approach was adopted in this study since the support for agricultural decision making in the U.S. is typically organized along political boundaries, and counties are generally the organizational unit where information is sought (Elias et al., 2018). In addition to countywide analysis, the data were analyzed based on the nine climate divisions of Oklahoma. According to Illston et al. (2004), climate divisions are generally used as the unit of reporting by the U.S. Department of Agriculture and each climatic region is estimated to have homogeneous weather and climatic 
conditions. The average annual rainfall in Oklahoma decreases sharply from east to west. The southeast receives upwards of $1400 \mathrm{~mm}$, compared to about $430 \mathrm{~mm}$ in the Panhandle. The average annual air temperatures of Oklahoma range from around $17^{\circ} \mathrm{C}$ in the south to $14^{\circ} \mathrm{C}$ in the north and $12^{\circ} \mathrm{C}$ in the western panhandle (OCS, 2019). Figure 1 presents the spatial distribution of the average annual air temperature across Oklahoma obtained from the Parameter-elevation Relationships on Independent Slopes Model (PRISM) database (Daly et al., 2008).

\section{Cotton Planting and Termination Dates}

In order to estimate potential crop yield, Van Wart et al. (2013a) reported the need for specification of planting and termination dates. As explained earlier, the planting date for cotton is critical to attain a good stand and achieve the potential lint yield. Several previous studies have used fixed planting dates across study years (Van Wart et al., 2013b; Ray et al., 1999; Vaverka, 2018; Chen et al., 2019), which does not represent real-world practices. In this study, however, the planting date was variable in each year for each county. This variable date was estimated as the first date in each year when all of the following conditions were met: 1) the minimum soil temperature in the seed zone exceeded $\left.15.6^{\circ} \mathrm{C} ; 2\right)$ the five-day forecast for daytime minimum and maximum air temperatures were at least 10.0 and $26.7^{\circ} \mathrm{C}$, respectively (Boman and Lemon, 2005; Esparza et al., 2007); and, 3) the five-day forecast for heat unit accumulation was more than $27.8^{\circ} \mathrm{C} \cdot \mathrm{d}$ (Robertson et al., 2007). Due to the limited length of minimum soil temperature data from the Oklahoma Mesonet ( $<30$ years), this parameter was estimated for each county using linear regression models that were developed from the available data of minimum soil temperature at a depth of $0.10 \mathrm{~m}$ and air temperature following the procedure by Esparza et al. (2007) and Brown (2012). According to USDA-NASS (2010), the usual active planting and termination dates of cotton in Oklahoma range from 2 May to 18 June and 4 October to 24 December, respectively. These windows were used as guidelines to ensure the estimated planting and termination dates were reasonable. Since the planting date is one of the major agronomic factors that affect cotton growth and lint yield (Ullah et al., 2017), an additional analysis was performed to determine the magnitude of change in potential cotton lint yield as a result of planting one week earlier and one week later than the estimated optimum planting date in each year for each county. The crop was terminated on the first date when the average air temperature was equal or less than $-2.2^{\circ} \mathrm{C}$ (first freeze) or on November 11, whichever happened first in each year (Esparza et al., 2007). According to USDA-NASS (2010), the usual active harvesting dates of cotton in Oklahoma range from 15 October to 9 December. Hence, 11 November, which is the average date, was used for cotton termination when the first freeze did not occur in a given year in a particular county.

\section{Total Heat Units and Potential Cotton Lint YIELDS}

In this study, 38 years (1981-2018) of gridded daily minimum and maximum air temperature data at $4 \mathrm{~km}$ resolution were obtained from the PRISM database. The PRISM data were used instead of the data from the Oklahoma Mesonet network of surface observing stations (Brock et al., 1995) because at least 30 years of data is required for the kind of analysis conducted in this study. The Mesonet network of weather stations in Oklahoma was established in 1994 and most of the weather variables in the early years have a large number of missing values. A comparative analysis of the PRISM and the Mesonet data for the available years revealed high correlations, with $\mathrm{R}^{2}$ values ranging from 0.89 to 0.92 . Similarly, Behnke et al. (2016) found a close match $\left(\mathrm{R}^{2}>\right.$ $0.90)$ and identical spatial variability of gridded air temperature values from PRISM and ground-based weather stations across the U.S. The air temperature data were used to calculate the daily heat units (HU) following the equation by McMaster and Wilhelm (1997) expressed as:

$$
H U\left({ }^{\circ} \mathrm{C}\right)=\frac{\left(T_{\max }+T_{\min }\right)}{2}-T_{b}
$$

where $T_{\max }, T_{\min }$, and $T_{b}$ are the daily maximum, minimum, and base air temperatures, respectively. $T_{b}$ is crop-specific and defines the minimum threshold that allows crop physiological growth. In this study, $\mathrm{T}_{\mathrm{b}}$ for cotton was assumed as $15.6^{\circ} \mathrm{C}$ (Esparza et al., 2007).

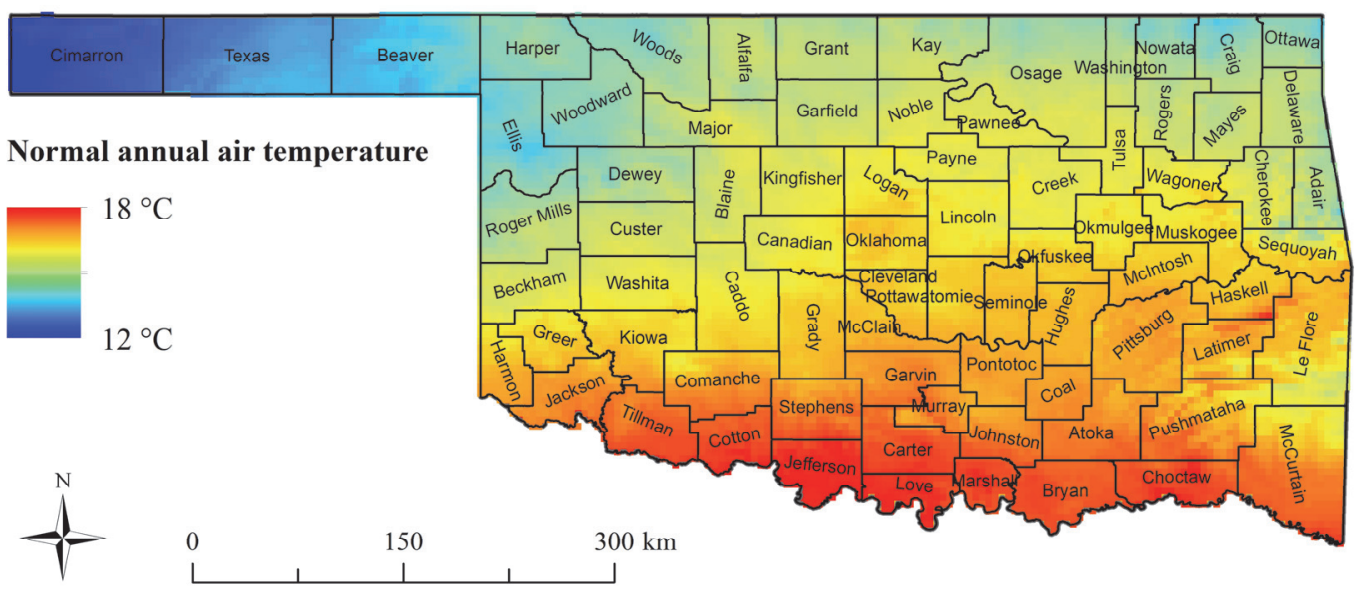

Figure 1. The 30-year (1981-2010) normal annual air temperature across Oklahoma. 
The county-wide potential cotton lint yield (PCLY) in each year was calculated based on the total heat units (THU) accumulated between planting and termination dates. A number of studies have developed THU-PCLY relationships under relatively good management and no water stress conditions for cotton (Wanjura et al., 2002; Gowda et al., 2007). Wanjura et al. (2002) developed a regression equation with THU data ranging between $1092^{\circ} \mathrm{C} \cdot \mathrm{d}$ and $1366^{\circ} \mathrm{C} \cdot \mathrm{d}$. The applicability of the equation by Wanjura et al. (2002) for THUs less than $1092^{\circ} \mathrm{C} \cdot \mathrm{d}$ and above $1366^{\circ} \mathrm{C} \cdot \mathrm{d}$ is not known. On the other hand, Gowda et al. (2007) developed THU-PCLY relationships that are inclusive of all THU ranges. Since thermal conditions vary largely across years and counties of Oklahoma, the relationships suggested by Gowda et al. (2007) were used in this study:

$$
P C L Y=0 \text { when } T H U<800^{\circ} \mathrm{C} \cdot d
$$

$$
\begin{aligned}
& P C L Y= \\
& {\left[\frac{T H U-800}{41.7}\right] * 112.5 \text { when } 800<T H U<1000^{\circ} \mathrm{C} \cdot d} \\
& P C L Y= \\
& {\left[5+\frac{T H U-1000}{41.7}\right] * 112.5 \text { when } T H U>1000^{\circ} \mathrm{C} \cdot d}
\end{aligned}
$$

These relationships were developed following the assumption that no cotton lint yield (PCLY $=0)$ is produced when THU is less than $800^{\circ} \mathrm{C} \cdot \mathrm{d}$. The second assumption was that one mature boll and four additional bolls at $85 \%$ maturity are produced by a cotton plant that accumulates $1000^{\circ} \mathrm{C} \cdot \mathrm{d}$ heat units. The last assumption was that every $41.7^{\circ} \mathrm{C} \cdot \mathrm{d}$ accumulated above $1000^{\circ} \mathrm{C} \cdot \mathrm{d}$ heat units would produce one more harvestable cotton boll per plant. The above relationships assumed the base temperature for cotton to be a conservative parameter, which means that there is no varietal response to base temperature.

In order to understand the effects of climate variability on THU and PCLY, which in turn help producers set realistic goals for planning purposes in their respective counties and climate divisions, exceedance probabilities were calculated. This was done by following the procedure highlighted by Esparza et al. (2007), which involved ranking the countywide PCLYs in decreasing order and estimating the exceedance probability $(\mathrm{P})$ using the following equation:

$$
P=\frac{N}{n+1}
$$

where $\mathrm{N}$ is the rank of the annual estimated value and $\mathrm{n}$ is the total number of years ( 38 in this study). Based on the plotted curves using the estimated $\mathrm{P}$, three scenarios were considered for mapping county-based PCLY values expected to occur i) every year $(\mathrm{P} \approx 0.99)$; ii) 4 out of 5 years $(\mathrm{P} \approx 0.80)$; and, iii) 3 out of 4 years $(\mathrm{P} \approx 0.75)$.

To demonstrate the performance of the relationships and magnitude of yield gaps, the estimated PCLYs for two counties (Jackson and Beckham) were compared with available county average lint yields of irrigated cotton obtained from USDA-NASS. The estimated annual PCLYs were expected to be above the USDA-NASS county average cotton lint yields. Furthermore, the PCLYs were also compared with the observed cotton lint yields obtained from the irrigated variety trials that were conducted by Oklahoma State University (OSU) in the same two counties between the years 2001 and 2017. University experiments benefit from properly developed and executed cultural practices, including planting and termination dates, fertilization, pest and disease control, irrigation application, and crop termination for various varieties and cultivars. Hence, cotton lint yield measurements from these experiments were expected to generally fall between PCLYs and county averages.

\section{RESULTS AND DISCUSSION COTTON PLANTING AND TERMinATION DATES}

The first condition for determining the cotton planting date was based on minimum soil temperature. To estimate the minimum soil temperature, two linear regression models were developed based on the maximum and minimum air temperatures for each county. Large $\mathrm{R}^{2}$ values $(>0.80)$ were achieved for all models. However, models developed based on the minimum air temperature achieved $\mathrm{R}^{2}$ values consistently larger than those developed from maximum air temperature. The first planting date criterion of the minimum soil temperature reaching $15.6^{\circ} \mathrm{C}$ was considered met when the estimated values from both models satisfied the condition. The ranges of minimum and maximum air temperatures that caused the minimum soil temperature to reach the $15.6^{\circ} \mathrm{C}$ threshold were $9.5-12.0^{\circ} \mathrm{C}$ and $22.0-27.5^{\circ} \mathrm{C}$, respectively. Whereas the minimum air temperature requirements to meet this criterion were close across the counties, there were noticeable differences for the maximum air temperature. Relatively higher maximum air temperatures were required for counties in the Panhandle compared to other climate divisions. Figure 2 presents the linear regression models for one central county in each of the nine Oklahoma climate divisions as examples.

When only the first condition of determining planting date (minimum soil temperature $>15.6^{\circ} \mathrm{C}$ ) was considered and the other two conditions (five-day forecasts of temperature and $\mathrm{HU})$ were omitted, the resultant planting dates ranged from early March to late April. These dates are too early to allow good cotton stand under Oklahoma conditions and are also out of the usual planting window reported by USDA-NASS. The insufficiency of soil temperature as the sole predictor of planting date observed in the present study agrees with the findings of Mauget et al. (2019) who indicated the importance of combining soil temperature at planting with the air temperature forecasts when making cotton planting decisions. When air temperature and HU forecasts were combined with soil temperature data, the resultant cotton planting dates shifted considerably, with $90 \%$ of all the dates for county-year combinations ranging from 25 April to 30 June. About $73 \%$ of these planting dates in the highlighted range occurred in the month of May. These planting dates are in line with the usual planting dates in Oklahoma (Larson and Mapp, 1997; USDA-NASS, 2019). The estimated planting dates for counties in the northern part of the state were relatively later compared to those in the southern part of the state for the same years. Figure 3 presents the percentage 

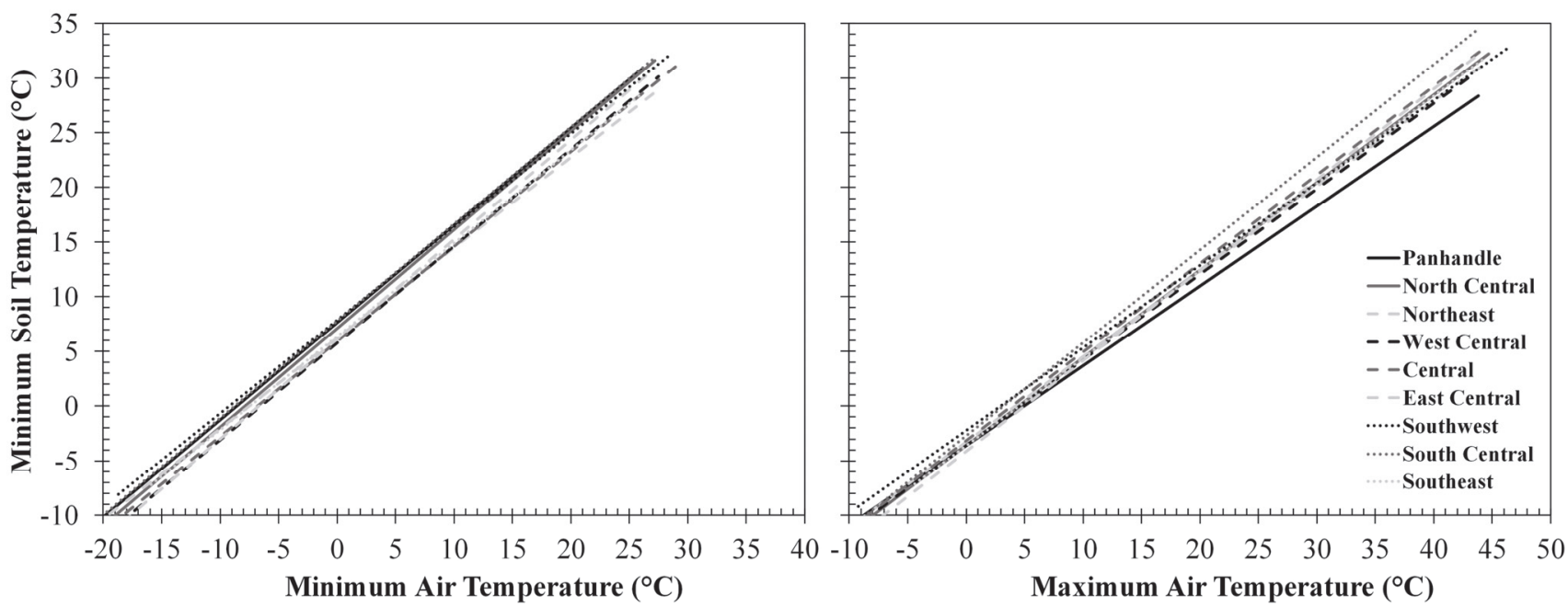

Figure 2. Linear regression lines for the models developed to estimate minimum soil temperature for central counties in each climate division.

of years (out of 38 years of study) when average planting dates occurred in each of the specified 15-day periods for a representative county in each climate division of Oklahoma.

The termination date in almost every year for all counties was 11 November because the first freeze happened later than this date. Crop termination was a few days earlier for the central and northern counties in 1991 and 1993 where the average air temperatures of less than $-2.2^{\circ} \mathrm{C}$ were recorded on 3 November and 31 October, respectively.

\section{TOTAL Heat UNITS}

The THUs were generally above $1000^{\circ} \mathrm{C} \cdot \mathrm{d}$ for most counties as shown in figure 4. Countywide THUs varied from $944^{\circ} \mathrm{C} \cdot \mathrm{d}$ in the Cimarron County (Panhandle) to $1708^{\circ} \mathrm{C} \cdot \mathrm{d}$ in Tillman county (Southwest) when averaged over the entire 38 years of study. Cimarron was the only county out of the 77 that had a long-term average THU of less than $1000^{\circ} \mathrm{C} \cdot \mathrm{d}$. Overall, the results from this study showed an increase in THUs from the northern to the southern counties of the state, similar to what was reported for the Ogallala Aquifer region by Esparza et al. (2007). Late attainment of conducive planting conditions along with lower air temperatures appeared to be the main reasons for low THUs in the northern counties of Oklahoma. The fact that southern counties attained higher THUs appears to be the major reason why these areas are historically the predominant cotton growing areas in Oklahoma (Evers et al., 1998).

Gowda et al. (2007) and Esparza et al. (2007) found cotton production to be viable at $1000^{\circ} \mathrm{C} \cdot \mathrm{d}$ THUs in the Central High Plains. Using a similar benchmark, the results from this study showed that 76 of the 77 counties in Oklahoma might be appropriate for cotton production based on heat unit availability. Another study by Freeland et al. (2006) reported that current cotton cultivars require THUs between 1195 and $1275^{\circ} \mathrm{C} \cdot \mathrm{d}$ to produce an acceptable lint yield. Seventy-four of the 77 counties attained long-term average THUs of more than $1195^{\circ} \mathrm{C} \cdot \mathrm{d}$ and 65 counties had THUs above $1275^{\circ} \mathrm{C} \cdot \mathrm{d}$, another indication that most counties in Oklahoma have adequate heat units for cotton production.

\section{Potential CotTon Lint Yield}

The 38-year average PCLYs followed the same pattern as THUs, with the Cimarron and Tillman counties attaining the smallest and largest lint yields at 407 and $2472 \mathrm{~kg} \mathrm{ha}^{-1}$, respectively. The long-term PCLYs were greater than $1000 \mathrm{~kg}$ $\mathrm{ha}^{-1}$ for $97 \%$ of the counties (fig. 5). Similar to the findings of Glade et al. (1996), the results from this study suggest the high risks associated with cotton production in the northern areas due to the variable and shorter growing seasons.

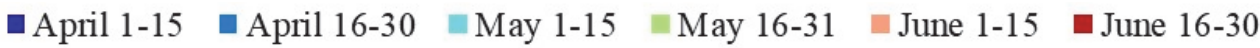

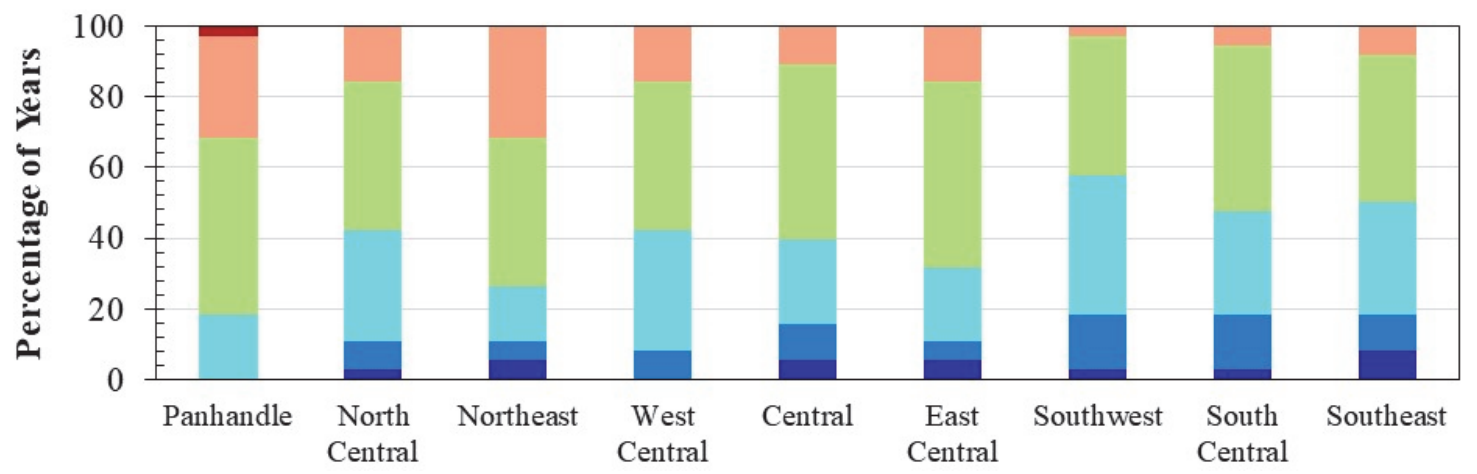

Figure 3. Percentage of years when planting dates occurred in the specified 15-day periods for a representative county in each climate division. 


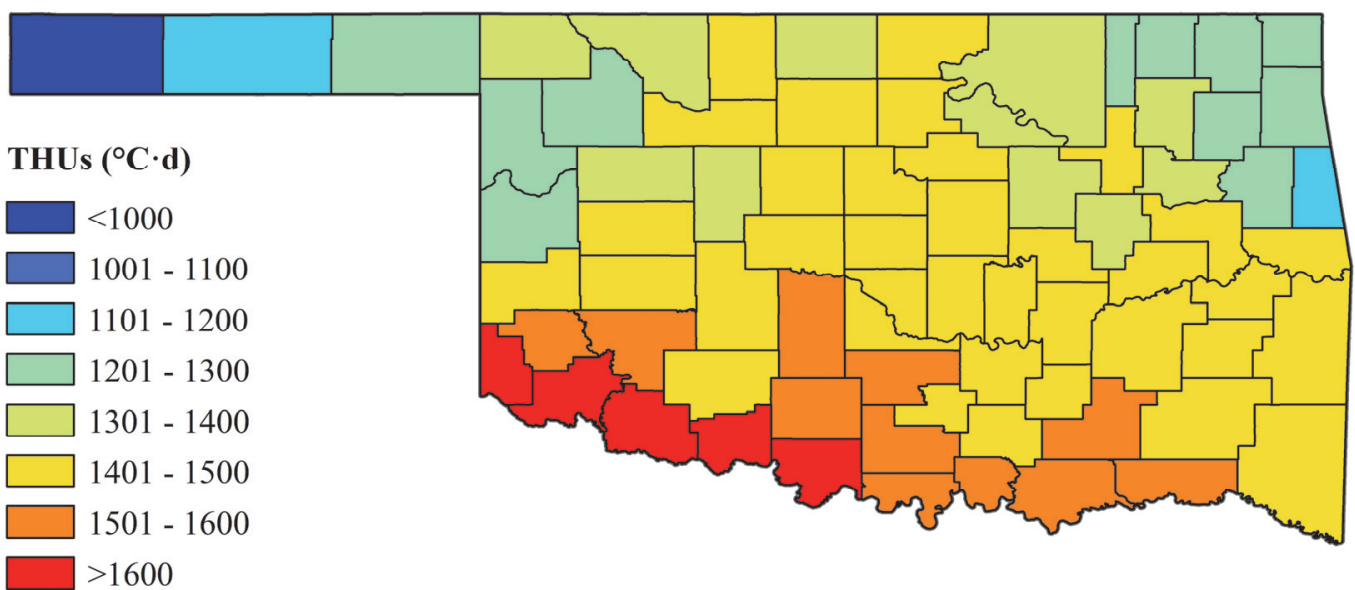

Figure 4. Total heat units (THUs) averaged over the 38 years of study.

The predicted PCLYs and the observed cotton lint yields from OSU irrigated variety trials conducted in Jackson and Beckham counties were compared with the USDA-NASS average county lint yields. The USDA-NASS yields were lower than the PCLYs in the two counties, an indication of the existence of large yield gaps. On the other hand, the predicted PCLYs for the two counties were generally within or above the observed lint yields from the variety trials. Considering that the potential cotton lint yield relationships used in this study were developed based on heat unit availability only, these results suggest that the model can be used to reasonably predict PCLY in Oklahoma. Figure 6 presents the PCLYs, USDA-NASS county average cotton lint yields, and box plots of the measured cotton lint yields at the variety trials for Jackson and Beckham counties for the years when the data were available.

As seen in figure 6, the difference between the USDANASS county average lint yield and the PCLY became smaller with time for Jackson County. In some of these years, the county average yields were within the range of yields from the variety trials. These results corroborate the findings of other studies that reported an increase in average cotton lint yields in the U.S. and across the world (Evans and Fischer, 1999; Constable and Bange, 2015). In Oklahoma, the narrowing of cotton yield gap could be attributed to improved agronomic practices resulting from comprehensive extension programs and incorporation of weather data in management decisions by cotton producers.

\section{Variability In Potential Cotton Lint Yields}

The annual PCLYs from the pooled data of all counties across the 38 years ranged from 0 to $3559 \mathrm{~kg} \mathrm{ha}^{-1}$. The largest PCLY determined in this study was similar to the potential lint yield of $3500 \mathrm{~kg} \mathrm{ha}^{-1}$ reported by Constable and Bange (2015) for current cotton varieties. When each county was considered separately, the PCLY data showed significant inter-annual variability over the 38 -year period. The largest variations were mainly in northeast and Panhandle counties. For instance, Washington County in the northeast and Cimarron County in the Panhandle had PCLYs that ranged from 0 to $2325 \mathrm{~kg} \mathrm{ha}^{-1}$ and 0 to $1160 \mathrm{~kg} \mathrm{ha}^{-1}$, respectively. On the other hand, inter-annual variabilities of PCLYs were smaller in the southern counties. Jefferson County (South Central) had the smallest inter-annual variability with PCLYs ranging between 1736 and $3433 \mathrm{~kg} \mathrm{ha}^{-1}$. The coefficient of variation $(\mathrm{CV})$, defined as the ratio of the standard deviation to the mean, of PCLY over the 38 years, ranged from $16 \%$ in the southern counties to $77 \%$ in the Cimarron County (Panhandle). Figure 7 presents the CV of PCLYs for

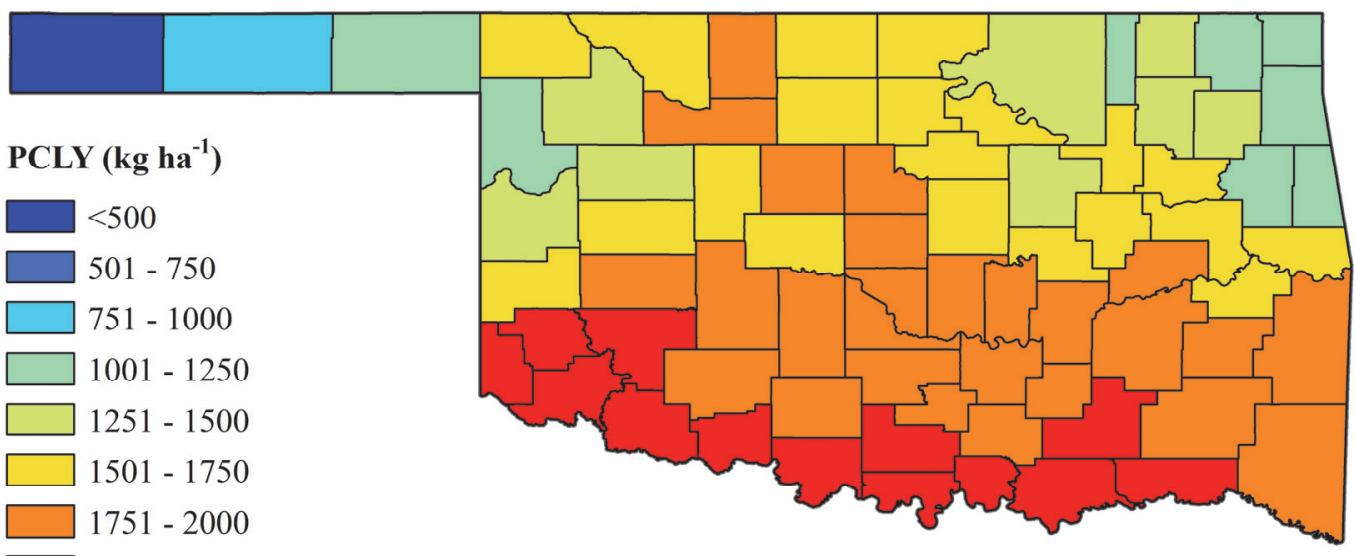

Figure 5. Potential cotton lint yield (PCLY) averaged over the 38 years of study. 

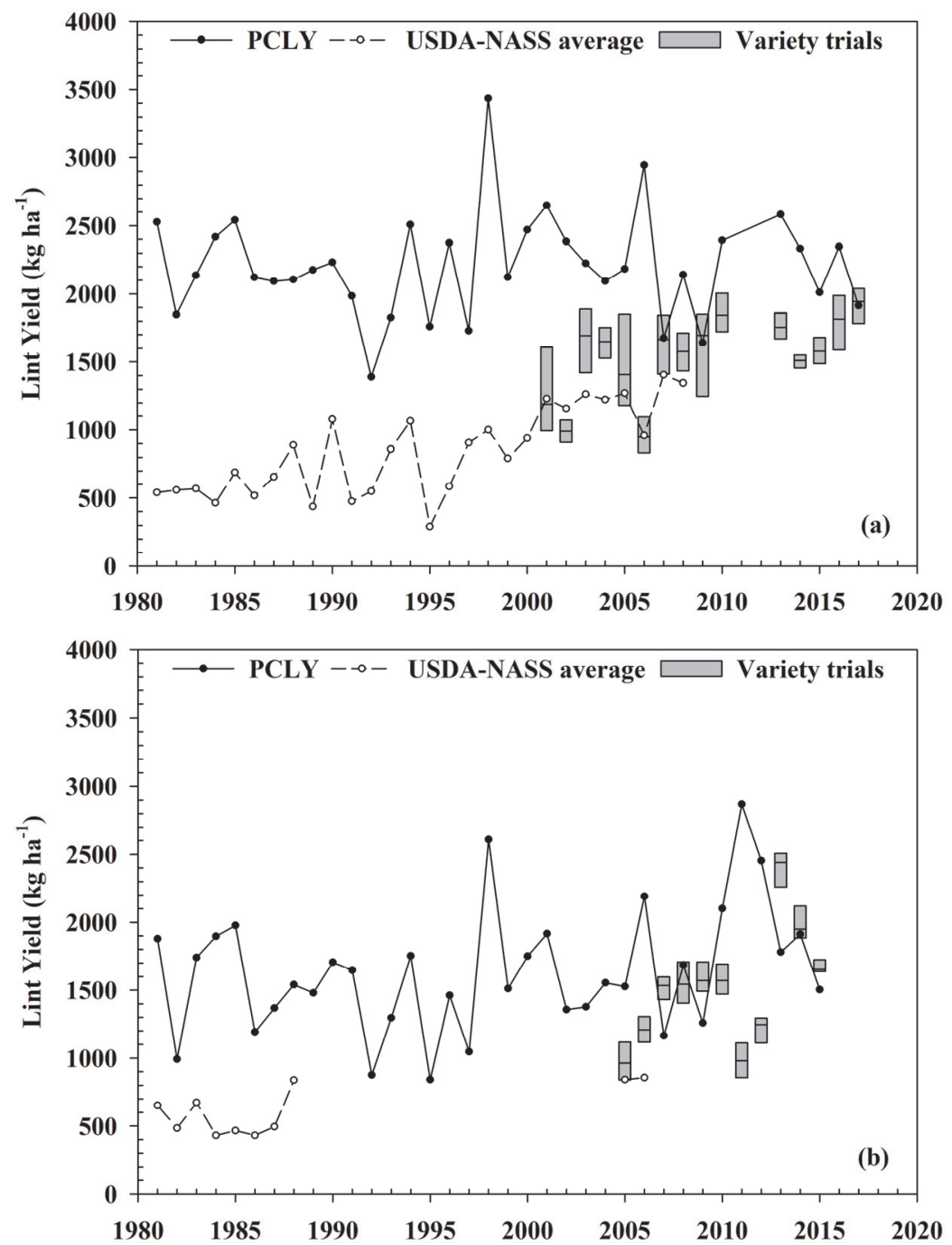

Figure 6. Potential cotton lint yield (PCLY), USDA-NASS county average lint yield, and measured lint yield at variety trials for Jackson (a) and Beckham (b) counties.

all counties of Oklahoma. Similar to the findings of Constable and Bange (2015) and Ullah et al. (2017), the results from this study suggest that inter-annual cotton lint yield variability is more profound in areas that are prone to smaller and more variable heat units.
About $94 \%$ of all counties attained their smallest PCLYs in years 1992 and 1995. The meteorological records from the Oklahoma Climatological Survey (OCS, 2019) for the summer season indicated that these two years were characterized by cool conditions. On the other hand, the largest PCLYs were observed in 1998, 2012, and 2011 for 55\%, 34\%, and

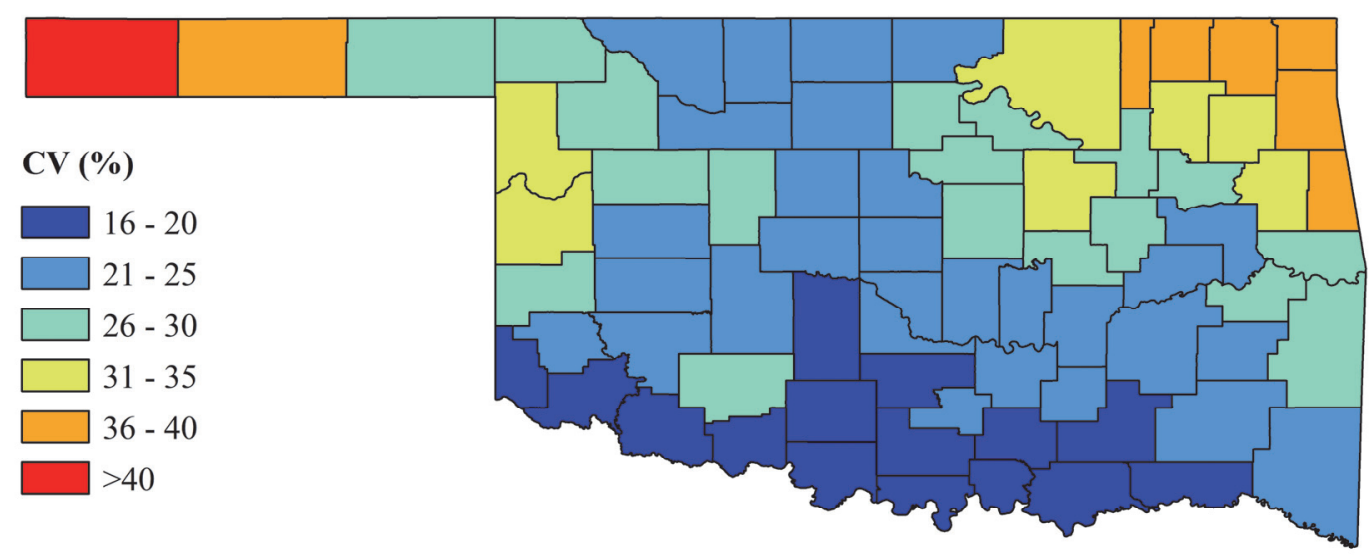

Figure 7. Coefficient of variation (CV) of potential cotton lint yield over 38 years of study. 


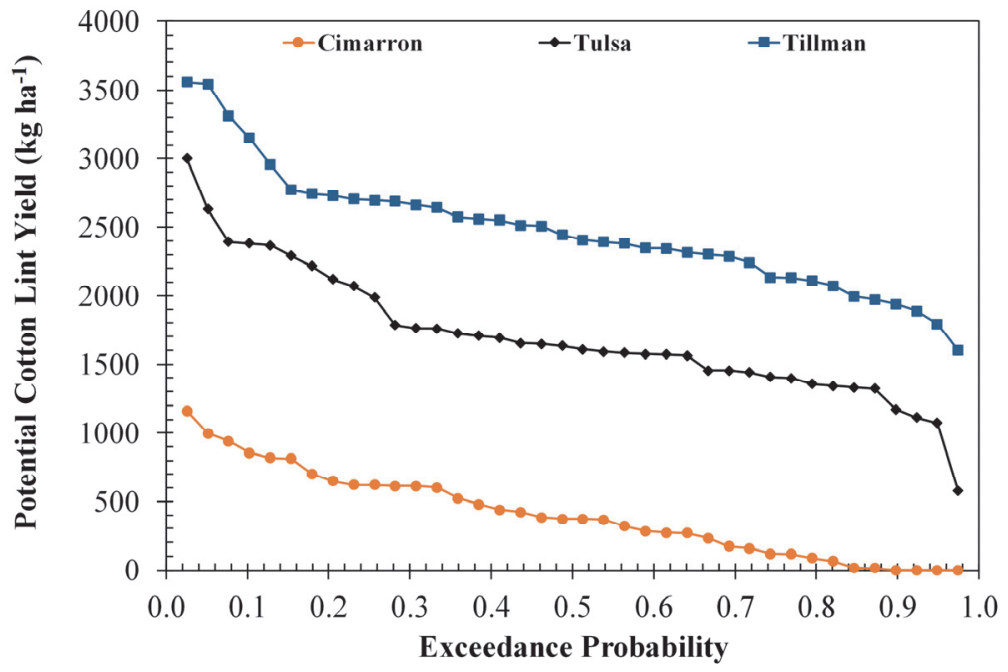

Figure 8. Exceedance probability curves for three counties with the smallest (Cimarron), median (Tulsa), and largest (Tillman) average potential cotton lint yields.

$11 \%$ of counties, respectively. All of these years were characterized by warm summers (OCS, 2019), and therefore attained more heat units, which led to larger PCLYs. These results reaffirm the findings of Masasi et al. (2020), who determined larger lint yields of irrigated cotton in years characterized by warmer conditions. However, it should be noted that the PCLY model implemented in the present study does not account for the impact of heat stress that could negatively impact cotton lint yield during years with extremely hot and dry conditions.

To improve the planning and management of cotton production considering the year-to-year weather variability in Oklahoma, the exceedance probability curves for each county were developed to analyze PCLY expectations in a specified time frame. The exceedance probability curves of the counties with the smallest, median, and largest average PCLYs are shown in figure 8 . The $\mathrm{P}$ curves for all other counties were in between those of the smallest and largest curves.
The expected PCLYs determined at $\mathrm{P}=0.50$ ranged from 371 to $2443 \mathrm{~kg} \mathrm{ha}^{-1}$ among all counties. To better demonstrate the spatial variability in expected PCLYs, the results for three scenarios of PCLYs expected every year $(\mathrm{P} \approx 0.99)$, expected 4 out of 5 years $(\mathrm{P} \approx 0.80)$, and expected 3 out of 4 years $(\mathrm{P} \approx 0.75)$ across all counties of Oklahoma are presented in figure 9.

In the Central and Southern High Plains region, Gowda et al. (2007) suggested a cotton lint yield level of $500 \mathrm{~kg}$ $\mathrm{ha}^{-1}$ for producers to realize profits. Potential lint yield expectations every year (fig. 9a) were more than $500 \mathrm{~kg} \mathrm{ha}^{-1}$ for $77 \%$ of all Oklahoma counties. These counties were located mostly in the southern and central areas of the state. Similar to Gowda et al. (2007), 4 of the 7 Oklahoma counties overlying the Ogallala Aquifer were found to be capable of producing $500 \mathrm{~kg} \mathrm{ha}^{-1}$ every year in this study. Yearly PCLYs upwards of $1250 \mathrm{~kg} \mathrm{ha}^{-1}$ were determined for the (a)

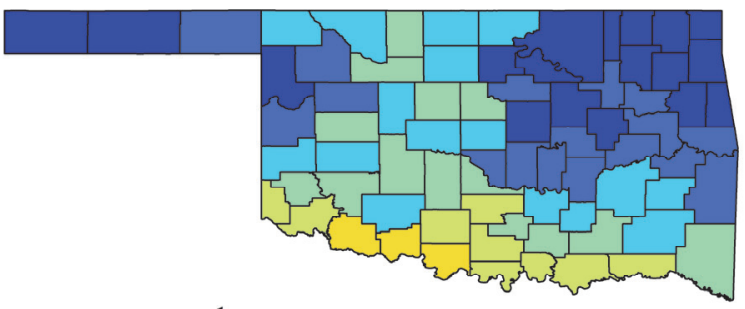

PCLY (kg ha ${ }^{-1}$ )

$$
\begin{aligned}
& <500 \\
& 501-750 \\
& 751-1000 \\
& 1001-1250 \\
& 1251-1500 \\
& 1501-1750 \\
& 1751-2000 \\
& >2000
\end{aligned}
$$

(b)

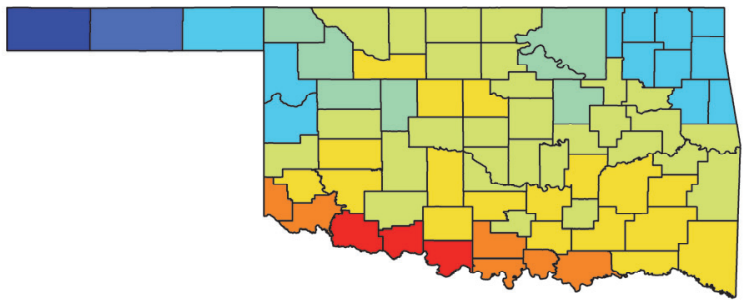

(c)

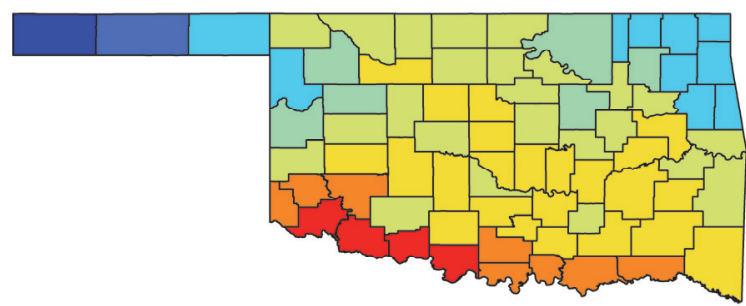

Figure 9. Spatial distribution of county-wide potential cotton lint yield (PCLY) expected every year (a), 4 out of 5 years (b), and 3 out of 4 years (c). 
southern-most counties of the state. These findings are consistent with the data from the OSU variety trials reported earlier where average annual lint yields for irrigated cotton were generally above $1250 \mathrm{~kg} \mathrm{ha}^{-1}$ for counties in the Southwest climate division such as Jackson and Tillman (Boman et al., 2017). These results explain why cotton production is concentrated in the southwestern part of the state.

The cotton lint yield expectations in 4 out of 5 years $(\mathrm{P} \approx$ $0.80)$ and 3 out of 4 years $(\mathrm{P} \approx 0.75)$ were more than $500 \mathrm{~kg}$ $\mathrm{ha}^{-1}$ for $99 \%$ of the counties of Oklahoma. Cimarron was the only county that had lint yield expectation of less than $500 \mathrm{~kg} \mathrm{ha}^{-1}$ for these two scenarios (fig. 9a and 9b). About $82 \%$ and $84 \%$ of the counties had lint yield expectations above $1000 \mathrm{~kg} \mathrm{ha}^{-1}$ in the 4 out of 5 years and 3 out of 4 years scenarios, respectively. Table 1 presents the percentage of counties in different PCLY categories based on the three mentioned scenarios.

For each year of study, the PCLYs of all counties in each of the nine Oklahoma climate divisions were averaged to obtain yearly regional estimates. Based on these yearly divisional PCLYs, exceedance probability curves were plotted to highlight the likelihood of expecting a certain PCLY in each climate division of Oklahoma. On average $(\mathrm{P}=0.50)$, the PCLY ranged from 1107 to $2100 \mathrm{~kg} \mathrm{ha}^{-1}$. At all probability levels, significantly larger PCLYs were determined in the Southwest and the South Central climate divisions compared to others. Additionally, the smallest PCLYs were determined in the Panhandle. Figure 10 shows the exceedance probability curves for the nine climate divisions.

Cotton lint yield is responsive to other environmental factors apart from the thermal conditions, such as rainfall amounts and distribution. According to Wells (1989), suboptimal environmental conditions in terms of air temperature, rainfall, light and pests limit the yield potential of cotton. Thus, despite the fact that most of the counties in Oklahoma generally have acceptable heat unit accumulation for most of the time, other environmental factors may render some areas unfeasible for cotton production. The southeastern areas of Oklahoma, for example, generally receive high amounts of rainfall and are characterized by humid conditions (Boyd, 2019; OCS, 2019). According to Ritchie et al. (2007), a cotton plant with plenty of water tends to develop excessive vegetative growth, which promotes boll rot and fruit abscission and ultimately reduced lint yield. Thus, cotton may not be the most ideal crop in these areas despite the availability of heat units. In this case, more research on the effect of the highlighted factors on potential cotton production in these areas is necessary in order to provide producers with the appropriate recommendations.

Table 1. Percentage of counties in different potential cotton lint yield (PCLY) categories under three exceedance probability scenarios.

\begin{tabular}{cccc}
\hline PCLY $\left(\mathrm{kg} \mathrm{ha}^{-1}\right)$ & Every Year & 4 out of 5 Years & 3 out of 4 Years \\
\hline $0-500$ & 23 & 1 & 1 \\
$500-1000$ & 43 & 17 & 14 \\
$1000-1500$ & 30 & 47 & 38 \\
$1500-2000$ & 4 & 31 & 42 \\
$>2000$ & 0 & 4 & 5 \\
\hline
\end{tabular}

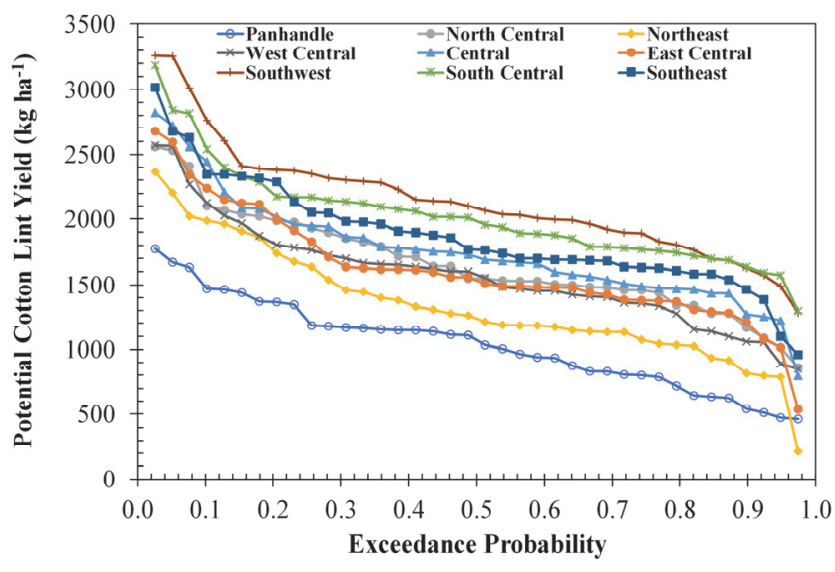

Figure 10. Exceedance probability curves for potential cotton lint yield of the nine climate divisions in Oklahoma.

\section{Effects of Planting Date on Potential Cotton LINT YIELD}

Since planting date plays an important role in estimating crop yield potential (Van Wart et al., 2013a), additional analysis was performed to determine the magnitude of change in PCLY as a result of planting one week earlier and one week later than the estimated planting date in each year and county. The lint yield increments due to planting a week earlier ranged from $3 \%$ to $14 \%$ and were generally similar among most counties. About $85 \%$ of counties achieved an increase of less than or equal to $5 \%$. The small lint yield changes experienced in most counties as a result of planting earlier suggest that the estimated planting dates in this study approximated the optimal planting dates for maximizing cotton lint yields. This is also an indication that the approach and criteria that were used for estimating the planting dates are applicable for Oklahoma conditions. Larger PCLY increases were determined for counties that usually experience less heat units, especially the Cimarron County in Oklahoma Panhandle (fig. 11a). In these counties, the average PCLYs are smaller because of the limited availability of heat units compared to other counties and therefore, larger changes in cotton lint yields are inevitable from small increments of heat units. Overall, the long-term average PCLY was increased by $4 \%$ on average across all counties when cotton was planted one week earlier than the estimated planting date in each year, which is similar to the findings of some previous studies (Gormus and Yucel, 2002; Mauget et al., 2019). Even though early planting appears to result in some lint yield increases, it is also important for producers to choose cotton varieties that can withstand potential cold stresses during the germination period (Mauget et al., 2019), otherwise they may risk losing revenue as a result of failed germination (requiring replanting).

As shown in figure 11(b), delaying planting by one week resulted in yield reductions ranging from $6 \%$ to $29 \%$. Similar to early planting, the largest PCLY changes occurred in $\mathrm{Ci}$ marron County and this can be explained by the same reasons outlined previously. Overall, delaying of planting by one week caused an average PCLY reduction of 9\% across all counties. Munir (2014) found similar results in Pakistan where cotton lint yields declined significantly by delaying 


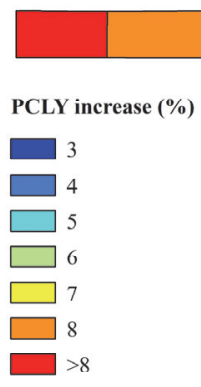

(a)

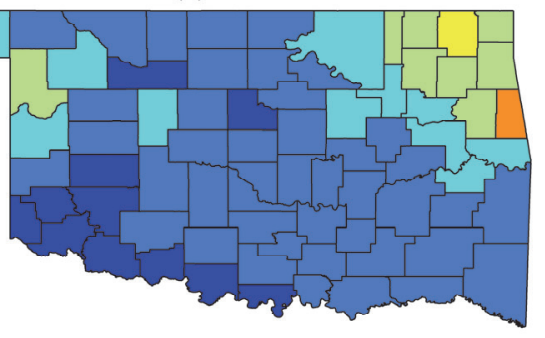

(b)

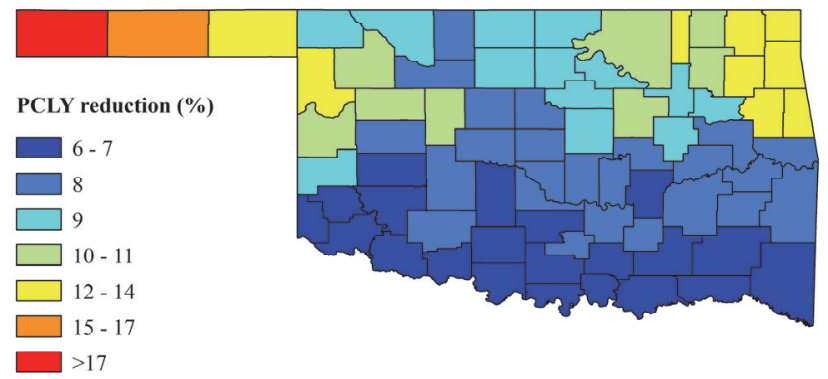

Figure 11. Percent changes in potential cotton lint yield (PCLY) due to (a) planting one week earlier and (b) one week later than the estimated planting date.

planting date by one week. The findings of the present study suggest the need for producers to pay critical attention to planting dates in regions that are generally prone to challenges of heat unit availability.

\section{CONCLUSiOnS}

The feasibility of growing cotton in Oklahoma was investigated by estimating the potential cotton lint yields (PCLYs) for all 77 counties of the state. The countywide PCLYs were estimated based on the total heat units (THUs) over a 38year period (1981-2018). An improved method of determining dynamic planting dates for cotton using soil temperature and forecasts of air temperature and heat units was developed. About $90 \%$ of the resultant planting dates occurred during 25 April to June 30, and these dates were mostly concentrated in May. This period falls within the USDA-NASS active planting dates for cotton in Oklahoma and illustrate the robustness of the criteria that was developed for estimating cotton planting date in this study. Additionally, 99\% and $97 \%$ of the counties attained the long-term average THUs of at least $1000^{\circ} \mathrm{C} \cdot \mathrm{d}$, and PCLYs above $1000 \mathrm{~kg} \mathrm{ha}^{-1}$, respectively. These long-term average THUs and PCLYs indicate that cotton production is feasible for most counties of Oklahoma if other factors apart from heat unit requirement are ignored. The PCLYs generally increased from the northern to the southern counties of the state. Furthermore, the results showed larger inter-annual variabilities of PCLYs in the northern counties compared to southern counties. In this study, delaying the planting date by only one week was found to cause PCLY reductions ranging from $6 \%$ to $29 \%$. Therefore, producers should carefully consider planting date for maximizing cotton lint yield. Overall, the data from this study showed high feasibility for cotton production in most counties of Oklahoma based on THUs. Future research should investigate other environmental factors such as rainfall and heat/cold stress in addition to thermal conditions in order to improve the potential cotton lint yield estimations.

\section{ACKNOWLEDGEMENTS}

This project was financially supported by the Agricultural Research Service, U.S. Department of Agriculture, under Agreement No. 58-3070-5-007. This research was a contribution from the Long-Term Agroecosystem Research
(LTAR) network. LTAR is supported by the United States Department of Agriculture.

\section{REFERENCES}

Behnke, R., Vavrus, S., Allstadt, A., Albright, T., Thogmartin, W. E., \& Radeloff, V. C. (2016). Evaluation of downscaled, gridded climate data for the conterminous United States. Ecol. Appl., 26(5), 1338-1351. doi:https://doi.org/10.1002/15-1061

Boman, R., \& Lemon, R. (2005). Soil temperatures for cotton planting. Texas A\&M AgriLife Ext. Retrieved from http://cotton.tamu.edu/General\%20Production/scs-200517\%20Soil\%20Temp.pdf

Boman, R., Goodson, J., Bull, L., \& Parker, R. (2017). Cotton extension annual reports. Oklahoma State University Department of Plant and Soil Sciences. Retrieved from http://cotton.okstate.edu/cttn-ext-annl-rprts

Boquet, D. J., \& Clawson, E. L. (2009). Cotton planting date: Yield, seedling survival, and plant growth. Agron. J., 101(5), 11231130. doi:https://doi.org/10.2134/agronj2009.0071

Boyd, V. (2019). Cotton's northward expansion in the Plains comes with a learning curve. Crop Soils, 52(3), 4-7. doi:https://doi.org/10.2134/cs2019.52.0301

Brock, F. V., Crawford, K. C., Elliott, R. L., Cuperus, G. W., Stadler, S. J., Johnson, H. L., \& Eilts, M. D. (1995). The Oklahoma mesonet: A technical overview. J. Atmospheric Oceanic Technol., 12(1), 5-19. doi:https://doi.org/10.1175/15200426(1995)012<0005:tomato >2.0.co;2

Brown, P. (2012). A good cotton planting forecast: Pinal County. Arizona Cooperative Ext. Retrieved from https://cals.arizona.edu/azmet/Good $\% 20$ Planting $\% 20$ Forecast $\%$ 20Pinal.pdf

Chen, X., Qi, Z., Gui, D., Gu, Z., Ma, L., Zeng, F., \& Li, L. (2019). Simulating impacts of climate change on cotton yield and water requirement using RZWQM2. Agric. Water Manag., 222, 231241. doi:https://doi.org/10.1016/j.agwat.2019.05.030

Constable, G. A., \& Bange, M. P. (2015). The yield potential of cotton (Gossypium hirsutum L.). Field Crops Res., 182, 98-106. doi:https://doi.org/10.1016/j.fcr.2015.07.017

Constable, G. A., \& Shaw, A. J. (1988). Temperature requirements for cotton. New South Wales Agriculture \& Fisheries. Retrieved from

https://www.dpi.nsw.gov.au/_data/assets/pdf_file/0003/710796 /Agfact-P5.3.5-Temperature-requirements-for-cotton.pdf

Daly, C., Halbleib, M., Smith, J. I., Gibson, W. P., Doggett, M. K., Taylor, G. H., ... Pasteris, P. P. (2008). Physiographically sensitive mapping of climatological temperature and precipitation across the conterminous United States. Int. J. Climatol., 28(15), 2031-2064.

doi:https://doi.org/10.1002/joc.1688 
Elias, E., Schrader, T. S., Abatzoglou, J. T., James, D., Crimmins, M., Weiss, J., \& Rango, A. (2018). County-level climate change information to support decision-making on working lands. Climatic Change, 148(3), 355-369. doi:https://doi.org/10.1007/s10584-017-2040-y

Esparza, A. M., Gowda, P. H., Baumhardt, R. L., Marek, T., \& Howell, T. A. (2007). Heat unit availability for cotton production in the Ogallala Aquifer region of the United States. $J$. Cotton Sci., 11( 3), 110-117.

Evans, L. T., \& Fischer, R. A. (1999). Yield potential: Its definition, measurement, and significance. Crop Sci., 39(6), 1544-1551. doi:https://doi.org/10.2135/cropsci1999.3961544x

Evers, A. J., Elliott, R. L., \& Stevens, E. W. (1998). Integrated decision making for reservoir, irrigation, and crop management. Agric. Syst., 58(4), 529-554. doi:https://doi.org/10.1016/S0308521X(98)00068-7

Franke, T. C., Kelsey, K. D., \& Royer, T. A. (2009). Pest management needs assessment for Oklahoma cotton producers. Division of Agricultural Sciences and Natural Resources, Oklahoma State University. Retrieved from

http://pods.dasnr.okstate.edu/docushare/dsweb/Get/Version10785/EPP-7081web.pdf

Freeland, J. T., Pettigrew, B., Thaxton, P., \& Andrews, G. L. (2006). Chapter 13A: Agrometeorology and cotton production. Retrieved from http://www.agrometeorology.org/filesfolder/repository/chapter13A_gamp.pdf

Glade Jr, E. H., Meyer, L., \& Stults, H. (1996). The cotton industry in the United States. Agricultural Economic Report No. 739. Washington, DC: Economic Research Service, USDA. Retrieved from https://www.ers.usda.gov/webdocs/publications/79922/aer739.pdf? $\mathrm{v}=42647$

Gormus, O., \& Yucel, C. (2002). Different planting date and potassium fertility effects on cotton yield and fiber properties in the Cukurova region, Turkey. Field Crops Res., 78(2), 141-149. doi:https://doi.org/10.1016/S0378-4290(02)00121-1

Gowda, P. H., Baumhardt, R. L., Esparza, A. M., Marek, T. H., \& Howell, T. A. (2007). Suitability of cotton as an alternative crop in the Ogallala Aquifer Region. Agron. J., 99(6), 1397-1403. doi:https://doi.org/10.2134/agronj2006.0275

Gwathmey, C. O., Leib, B. G., \& Main, C. L. (2011). Lint yield and crop maturity responses to irrigation in a short-season environment. J. Cotton Sci., 15(1), 1-10.

Howell, T. A., Evett, S. R., Tolk, J. A., \& Schneider, A. D. (2004). Evapotranspiration of full-, deficit-irrigated, and dryland cotton on the Northern Texas High Plains. J. Irrig. Drain. Eng., 130(4), 277-285. doi:https://doi.org/10.1061/(ASCE)07339437(2004)130:4(277)

Illston, B. G., Basara, J. B., \& Crawford, K. C. (2004). Seasonal to interannual variations of soil moisture measured in Oklahoma. Int. J. Climatol., 24(15), 1883-1896. doi:https://doi.org/10.1002/joc. 1077

Larson, J. A., \& Mapp, H. P. (1997). Cotton cultivar, planting, irrigating, and harvesting decisions under risk. J. Agric. Resour. Econ., 22(1), 157-173. Retrieved from http://www.jstor.org/stable/40986939

Marek, T., \& Bordovsky, D. (2006). Performance of ten cotton varieties in the Northern Texas High Plains. Texas J. Agric. Nat. Resour., 19, 48-61.

Masasi, B., Taghvaeian, S., Boman, R., \& Datta, S. (2019). Impacts of irrigation termination date on cotton yield and irrigation requirement. Agric., 9(2), 39. doi:https://doi.org/10.3390/agriculture9020039
Masasi, B., Taghvaeian, S., Gowda, P. H., Marek, G., \& Boman, R. (2020). Validation and application of AquaCrop for irrigated cotton in the Southern Great Plains of U.S. Irrig. Sci. doi:https://doi.org/10.1007/s00271-020-00665-4

Mauget, S., Ulloa, M., \& Dever, J. (2019). Planting date effects on cotton lint yield and fiber quality in the U.S. Southern High Plains. Agric., 9(4), 82. doi:https://doi.org/10.3390/agriculture9040082

McMaster, G. S., \& Wilhelm, W. W. (1997). Growing degree-days: One equation, two interpretations. Agric. For. Meteorol., 87(4), 291-300. doi:https://doi.org/10.1016/S0168-1923(97)00027-0

Morrow, M. R., \& Krieg, D. R. (1990). Cotton management strategies for a short growing season environment: Waternitrogen considerations. Agron. J., 82(1), 52-56. doi:https://doi.org/10.2134/agronj1990.00021962008200010011 $\mathrm{x}$

Munir, M. K. (2014). Growth and yield response of cotton to various agronomic practices. $\mathrm{PhD}$ diss. Faisalabad, Pakistan: University of Agriculture.

OCS. (2019). Climate of Oklahoma. Oklahoma Climatological Survey. Retrieved from https://climate.ok.gov/index.php/site/page/climate_of_oklahoma

Parthasarathi, T., Velu, G., \& Jeyakumar, P. (2013). Impact of crop heat units on growth and developmental physiology of future crop production: A review. J. Crop Sci. Techno., 2(1), 23193395.

Peng, S., Krieg, D. R., \& Hicks, S. K. (1989). Cotton lint yield response to accumulated heat units and soil water supply. Field Crops Res., 19(4), 253-262. doi:https://doi.org/10.1016/03784290(89)90097-X

Ray, S. S., Pokharna, S. S., \& Ajai. (1999). Cotton yield estimation using agrometeorological model and satellite-derived spectral profile. Int. J. Remote Sens., 20(14), 2693-2702. doi:https://doi.org/10.1080/014311699211741

Ritchie, G. L., Bednarz, C. W., Jost, P. H., \& Brown, S. M. (2007). Cotton growth and development. University of Georgia Cooperative Ext. Retrieved from http://hdl.handle.net/10724/12192

Robertson, B., Stewart, S., \& Boman, R. (2007). Planting and replanting decisions. National Cotton Council. Retrieved from https://www.cotton.org/tech/physiology/cpt/variety/upload/Plant ing-and-Replanting-Decisions-2007.pdf

Supak, J. R. (198/4). Understanding and using heat units. Texas Agricultural Extension Service. Retrieved from http://cotton.tamu.edu/General\%20Production/archunderstandingandusingheat.pdf

Tolk, J. A., \& Howell, T. A. (2010). Cotton water use and lint yield in four Great Plains soils. Agron. J., 102(3), 904-910. doi:https://doi.org/10.2134/agronj2009.0398

Ullah, K., Khan, M. I., Mahmood, Z., Iqbal, T., Muhammad, S., Haq, H. A., ... Hussain, S. (2017). Response of yield and related attributes of upland cotton to weather variables. American J. Plant Sci., 8(7), 1711. doi:https://doi.org/10.4236/ajps.2017.87118

USDA-NASS. (2010). Field crops: Usual planting and harvesting dates. Washington, DC: USDA-NASS. Retrieved from https://usda.library.cornell.edu/concern/publications/vm40xr56k

USDA-NASS. (2019). Washington, DC: USDA-NASS. Retrieved from https://quickstats.nass.usda.gov/

van Ittersum, M. K., Cassman, K. G., Grassini, P., Wolf, J., Tittonell, P., \& Hochman, Z. (2013). Yield gap analysis with local to global relevance: A review. Field Crops Res., 143, 4-17. doi:https://doi.org/10.1016/j.fcr.2012.09.009 
Van Wart, J., Grassini, P., \& Cassman, K. G. (2013b). Impact of derived global weather data on simulated crop yields. Global Change Biol., 19(12), 3822-3834.

doi:https://doi.org/10.1111/gcb.12302

Van Wart, J., Kersebaum, K. C., Peng, S., Milner, M., \& Cassman, K. G. (2013a). Estimating crop yield potential at regional to national scales. Field Crops Res., 143, 34-43. doi:https://doi.org/10.1016/j.fcr.2012.11.018

Vaverka, B. A. (2018). Initial evaluation of seasonal yield and irrigation demand forecasting frameworks for Oklahoma. MS thesis. Stillwater: Oklahoma State University.
Wanjura, D. F., \& Barker, G. L. (1985). Cotton lint yield accumulation rate and quality development. Field Crops Res., 10, 205-218. doi:https://doi.org/10.1016/0378-4290(85)90027-9

Wanjura, D. F., Upchurch, D. R., Mahan, J. R., \& Burke, J. J. (2002). Cotton yield and applied water relationships under drip irrigation. Agric. Water Manag., 55(3), 217-237. doi:https://doi.org/10.1016/S0378-3774(01)00175-5

Wells, R. (1989). Measurement of lint production in cotton and factors affecting yield. In Plant fibers (pp. 278-294). Berlin, Heidelberg: Springer. doi:https://doi.org/10.1007/978-3-64283349-6_15 